\title{
The last (plastic) straw?
}

Written by: James Philp, OECD Directorate for Science, Technology and Innovation

Last update: 2 March 2020

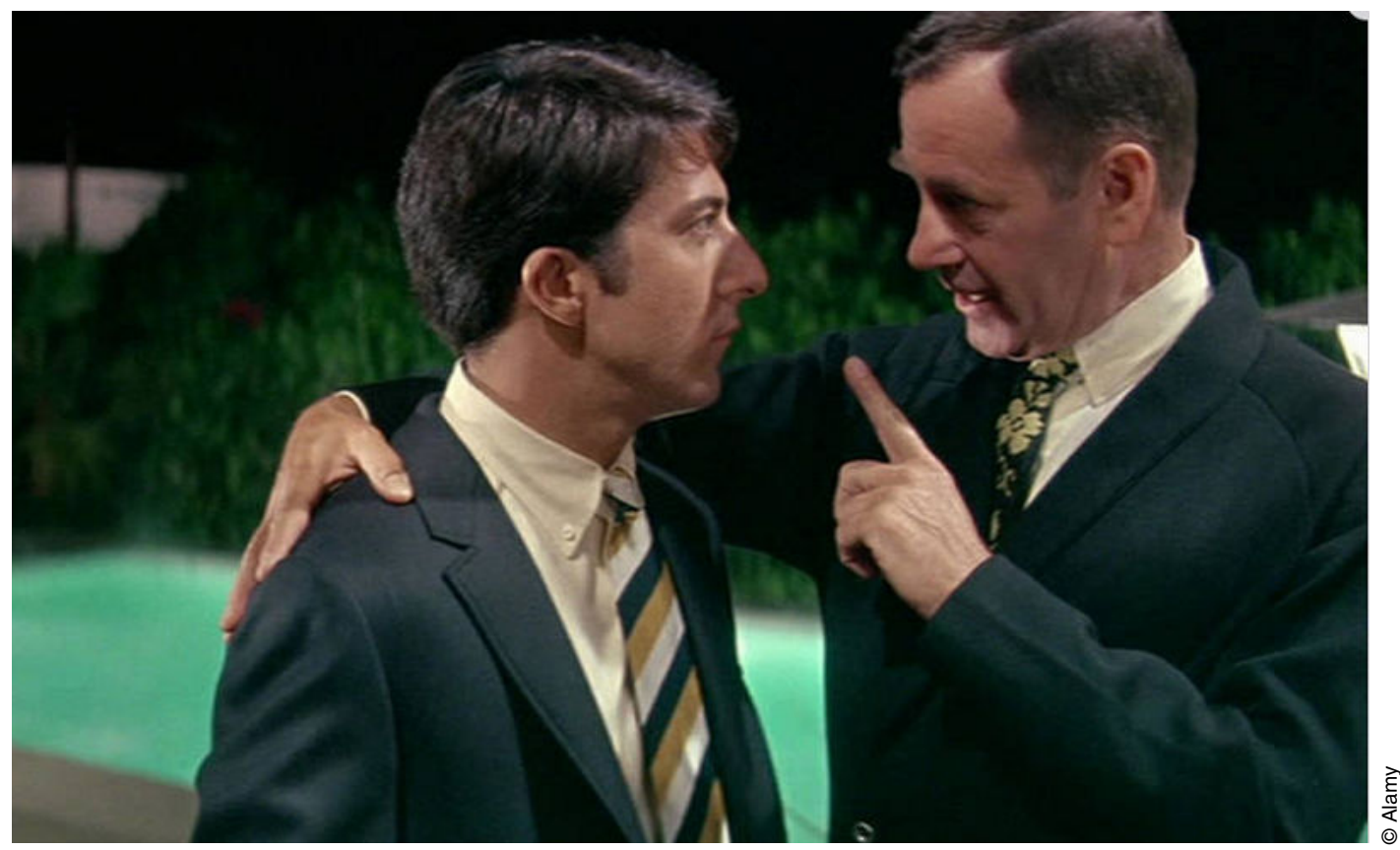

The last (plastic) straw image I Dustin Hoff man (left) in The Graduate, 1967

"I just want to say one word to you. Are you listening? Plastics." This infamous advice, delivered to Ben, played by Dustin Hoffman in the 1967 film, The Graduate, foresaw a great career in plastics.

And indeed, plastic is one of the most successful materials ever produced. So much so that about 300 million tonnes are produced each year. But the gloss has faded a little too, because of severe environmental problems which plastics pose. They are generally not biodegradable and hang around in the environment for decades or much longer. In 2018, a Pacific Ocean garbage patch was estimated to be 16 times larger than previously thought-it is 2 times the size of France. In the oceans, they can break down to microplastics, which can be taken up by, and interfere with, marine life. A report in January 2019 showed that every marine mammal in a survey contained microplastics, and the effects of this are largely unknown. If things do not change, by 2050 there will be more plastic waste in the oceans than fish. 
Biodegradable plastics can fill important niches, such as packaging, fruit and vegetable bags, coffee capsules, tea bags, and mulch films for growing fruit and vegetables. To date, their market penetration is minimal. And yet they can add value in a circular economy: they can be processed in industrial composting facilities or contribute to biogas generation for renewable energy.

A Finnish start-up, Sulapac, makes a packaging material that has plastic-like properties, yet biodegrades completely and leaves no microplastics behind. Made of sustainability-certified wood and natural binders, it can be used, for example, in cosmetics packaging to replace plastic jars. A new product for this Finnish company is a microplastic-free, marine biodegradable and mass-produceable drinking straw, an alternative to the oil-based plastic straws currently consumed by the billion each week. Who knows, they may even make a great career for graduates in the future.

COECD Observer March 2019

\section{References}

Nelms, S.E., Barnett, J., Brownlow, A., Davison, N. J., Deaville, R., Galloway, T. S., Lindeque, P. K., Santillo, D., and Godley, B. J. (2019), "Microplastics in marine mammals stranded around the British coast: ubiquitous but transitory?", Scientific Reports 9: 1075, doi.org/10.1038/s41598-018-37428-3 http://dx.doi.org/ https://www.oecd-ilibrary.org/industry-and-services/realising-the-circularbioeconomy_31bb2345-en

www.oecdobserver.org/finland50oecd 